IOSR Journal of Engineering (IOSRJEN)

e-ISSN: 2250-3021, p-ISSN: 2278-8719

Vol. 3, Issue 10 (October. 2013), ||V5|| PP 07-13

\title{
Status of Power Distribution In Jammu And Kashmir- A Critical Appraisal
}

\author{
Fayaz A. Mir, Mohd Rafi, Sajad A. Bhat, Er. Manzoor \\ 1, 2, (Student, Department Of Electronics And Communications Engineering SSM College Of Engineering And \\ Technology, University of Kashmir, India, \\ ${ }^{3}$ (Department Of Computer Sciences, North Campus, University Of Kashmir, India, \\ ${ }^{4}$ (Head of Electronics and Communications Engineering Department, SSM College Of Engineering, Kashmir,
}

\begin{abstract}
The main purpose of this paper is to make a detailed study of the existing Power distribution Sector in Jammu and Kashmir with special focus on finding the reasons for alarmingly high power losses. Different major aspects of distribution losses are identified and status and sustainability of power sector utilities is thoroughly studied so that it may provide further inputs to the concerned agencies for efficient management of the ailing distribution sector in the state.
\end{abstract}

Key words: - Aggregate Technical and Commercial Loss, Line Rigging, Meter Tampering, Power Distribution and Transmission, Unplanned Distribution Networks.

\section{INTRODUCTION}

There is no denying the fact that power sector is the backbone of economy whether at state level or at national level but high degree of reliability and quality power supply is also essential for the growth. India being fifth largest producer of electricity is still suffering from very high Transmission and Distribution losses and per capita consumption of energy was only 814kwh in 2011[1].In this paper we are going to thoroughly discuss where Jammu and Kashmir stands as far as distribution losses in power are concerned, what are the causes of huge Aggregate Technical and Commercial losses (AT\&C losses) and where are power utilities of state standing in the competitive market in comparison to other states of the country.

\section{HISTORY OF POWER DEVELOPMENT IN J\&K}

Power development in Jammu and Kashmir has a long and distinguished history. 9MW Mohra hydroelectric plant (shown in figure1), among the first of its kind in the subcontinent, was developed as early as 1905.The estimated hydel potential of the state is about 20,000 MW and in order to harness this potential in a sustained manner the government of Jammu and Kashmir has established the state power development corporation limited (jkspdcl) which has been incorporated as a private corporation on $16^{\text {th }}$ February 1995 . The corporation has presently twenty hydroelectric projects with installed capacity of 758.70MW.

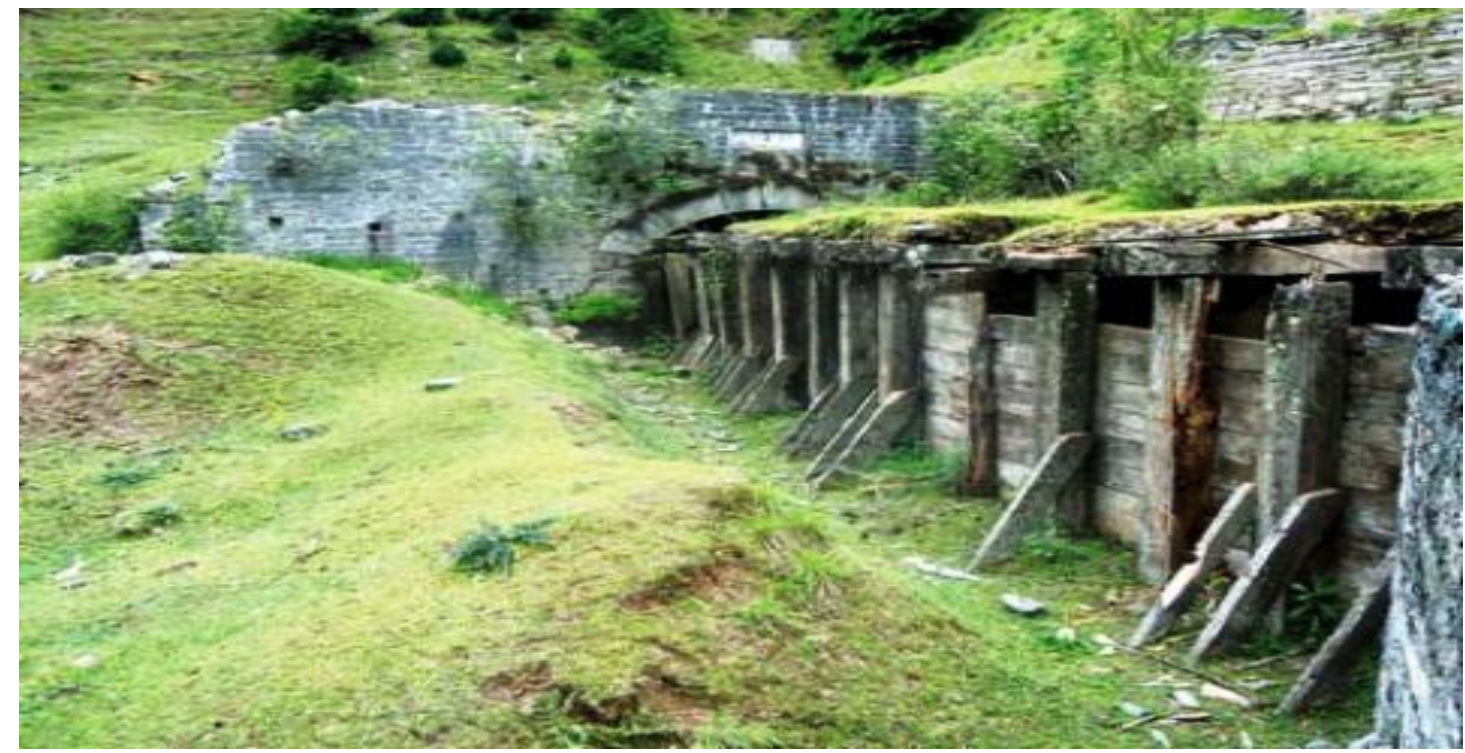

Figure1 Mohra hydroelectric plant [2] 
Some historical landmarks about Jammu and Kashmir power sector are given below

- Jammu and Kashmir became only second to Mysore to start a hydro power plant.

- Dr. Rajendra Prasad inaugurated Ganderbal project in 1955.

- In 1967-68, a 132KV Transmission line from kalakote to Chennai was established.

- Upper Sind hydel project Ganderbal was fully commissioned in 1974.

- 220kv Kishenpur-pampore transmission laid in 1996

- JKSERC established in 2004

- J\&K electricity act created in 2010.[3]

\section{TRANSMISSION AND DISTRIBUTION (T\&D) LOSSES}

Aggregate technical and commercial losses (AT\&C) are defined as difference between units into system and units for which payment is collected. Thus losses on account of non-realization of payments are not captured. In case of Jammu and Kashmir it has been consistently observed that payment of bills by consumers are delayed over a long period even extending up to six or eight months in some cases. Still AT\&C loss is the clearest measure of overall efficiency of distribution business as it measures both technical as well as commercial losses.

AT\&C LOSS $(\%)=\{($ Energy_Input-Energy_Realized $) * 100\} /$ Energy Input

Energy Realized $=($ Energy Billed $*$ Collection Efficiency $)$

Collection Efficiency $(\%)=\{($ Amount Realized*100)/Amount Billed $\}$

Average T\&D losses in India have been officially put at 26.15\%[4]but these losses are higher than $60 \%$ in some states including Jammu and Kashmir where it is about 67\%[4] ,highest in the country, as shown below.

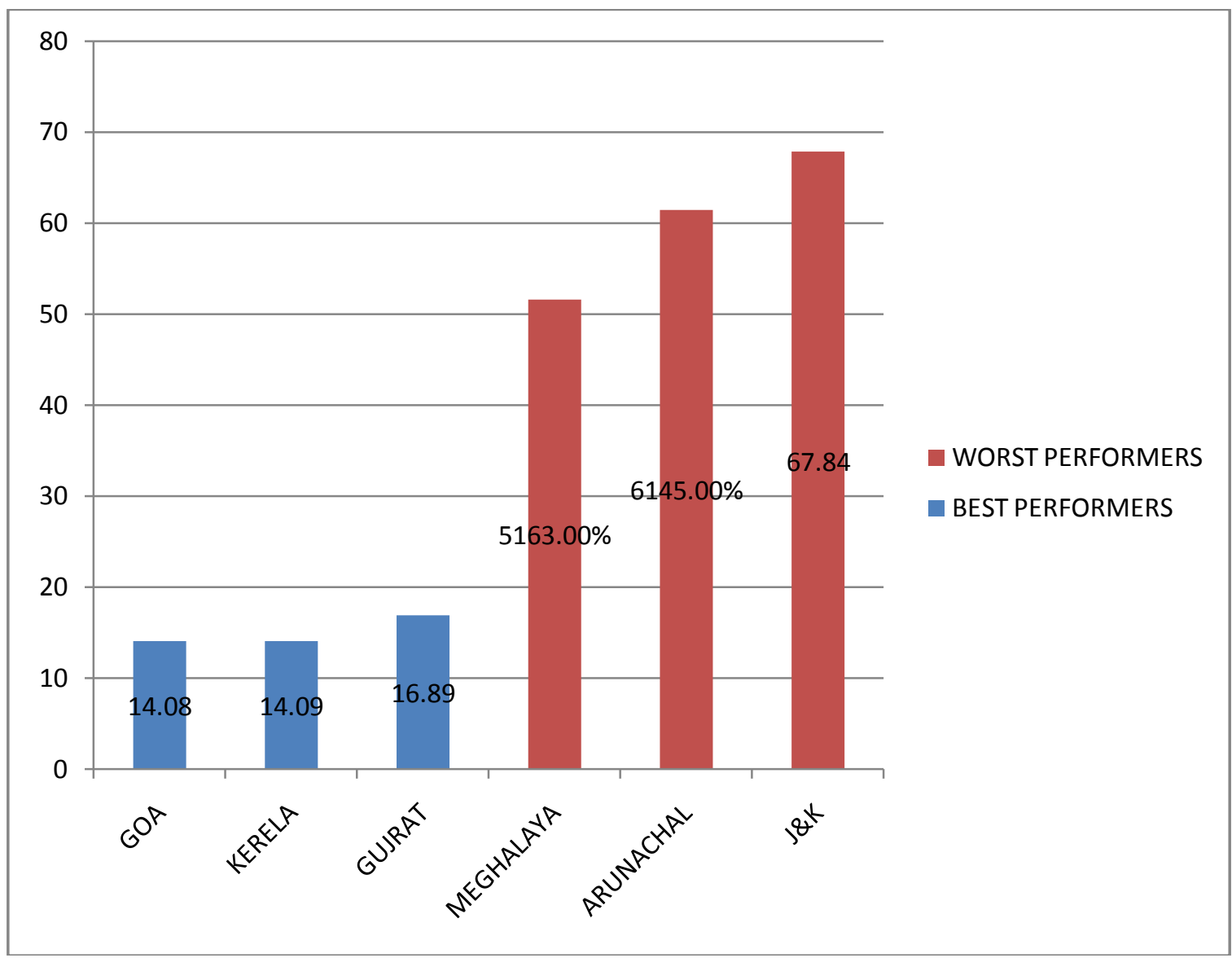

Figure 2.percentage losses when utilities selling directly to consumers [4]

There is a direct correlation between AT\&C losses and the low collection efficiency. During our studies we found that Jammu and Kashmir is also the worst performer as far as collection efficiency is concerned. A comparative analysis is shown below 


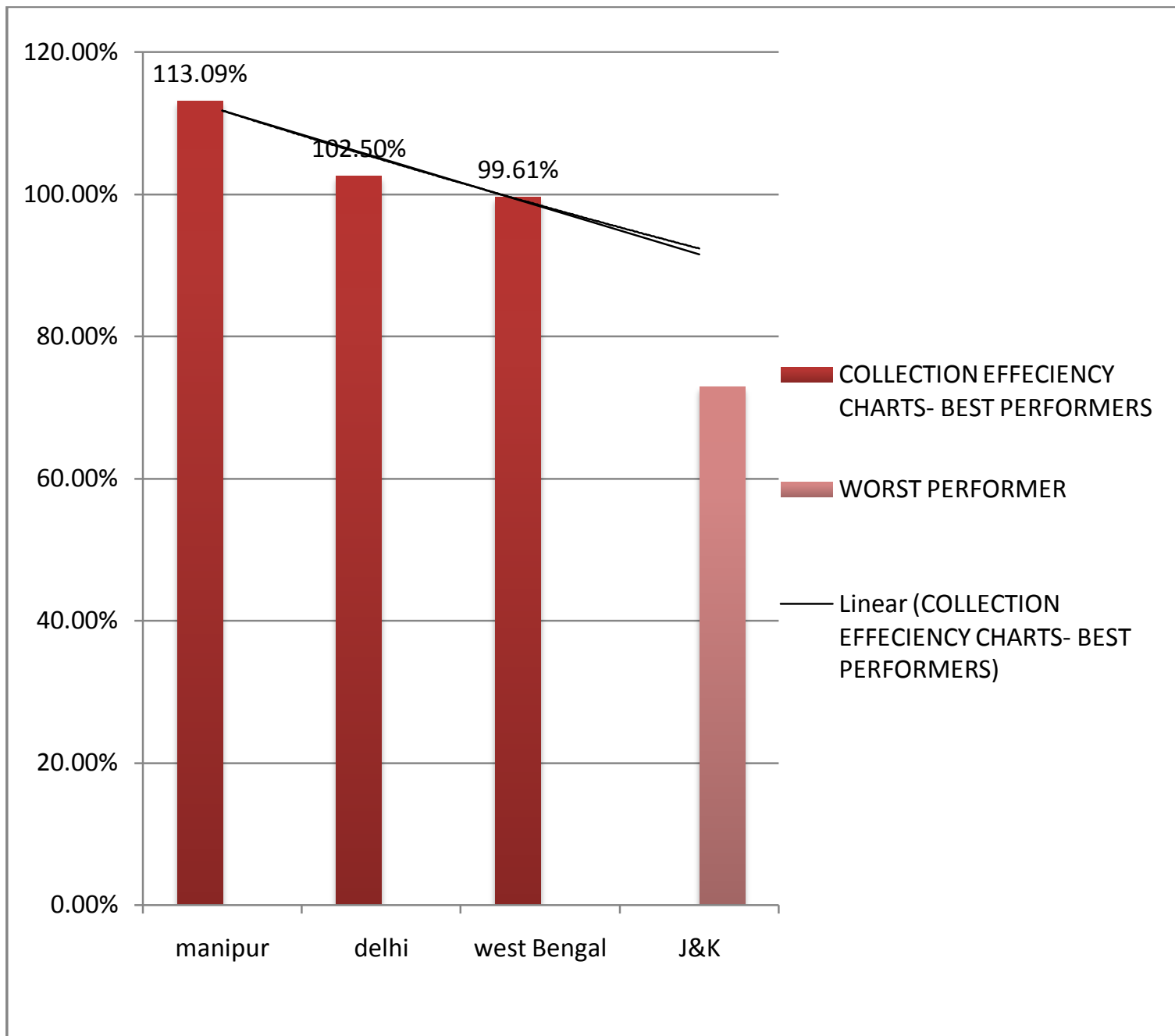

Figure 3showing collection efficiency [5]

\section{FACTORS LEADING TO HIGH LOSSES}

Some important factors that lead to alarmingly high AT\&C losses in Jammu and Kashmir are given below

\subsection{Inefficient electric power system}

In power systems, not all electricity generated reaches paying consumers because of many factors including inefficiencies and bad managerial practices but here we have discussed three important factors leading to highly inefficient power system in Jammu and Kashmir.

\subsubsection{Consumption by utility itself}

Some of the electricity generated will be consumed by the electric power system in order to produce and distribute the electricity but this consumption should be minimum possible so that distribution is economically viable. In case of Jammu and Kashmir, although some progress has been made but still pace of old equipment replacement is slow, rusted and outdated transformers are still used at some places which lead to heavy losses.

\subsubsection{Lengthy transmission lines}

Most of the population of Jammu and Kashmir lives in the valleys which are far away from the generating stations and being a power deficient state, most of the electricity is drawn from the Northern Grid thus transmission lines are lengthy which leads to higher T\&D losses.

\subsubsection{Gratis}

Third type of loss is gratis and illegal connections. Some electricity is provided free of cost to certain people and organizations and the number of illegal connections is very high.52000 [6] illegal connections have been regularized and the process has been speeded up. 


\section{POWER THEFT}

An electric system can never be $100 \%$ secure from theft. Although in some systems the amount of losses is small but financial loss is always high due to the large amount of electricity distributed. As Besit (2000) noted in the case of United States "in the US consensus seems to be that theft costs between $0.5 \%$ and $3.5 \%$ of annual gross revenue in the US. That seems a small amount -until you consider that US electricity revenues are in $\$ 280$ billion dollar range. Therefore between $\$ 1$ and $\$ 10$ billion worth of electricity was stolen". Thus we infer that a detailed study of power theft is necessary. The extent of theft depends on a numbers of factors ranging from utility management to cultural factors [7]. Some of the important factors that have been studied are

\subsection{Fraudulent means}

When a consumer deliberately tries to deceive the utility and make illegal use of electric power, it is known as fraud. A common practice here in Jammu and Kashmir is meter tampering and illegal hooking. Meter is tampered so that a lower reading of power is shown. During our surveys we found that some professional help is used by the residents to tamper the meter as shown in the figure below.

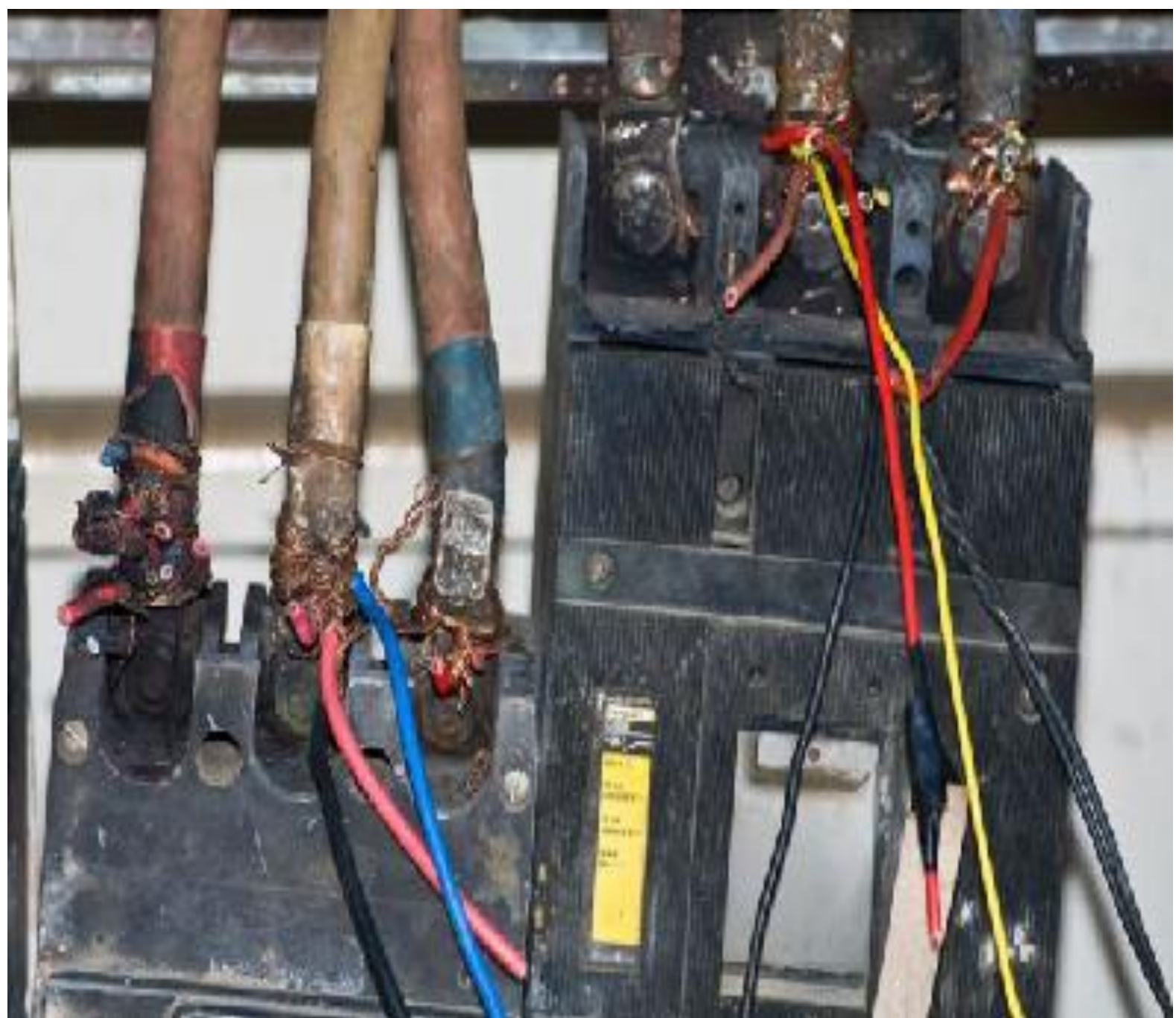

Figure4 Tampering of energy meters [7]

Illegal hooking is another type of electricity theft, here energy meter is bypassed by rigging a line from power source and this illegal power is mostly used during winters when hot water is needed thus huge amount of electricity is stolen during the months when generation is minimum at state level and most of electricity is bought from Northern Grid pushing an already overburdened electrical grid over the edge. 


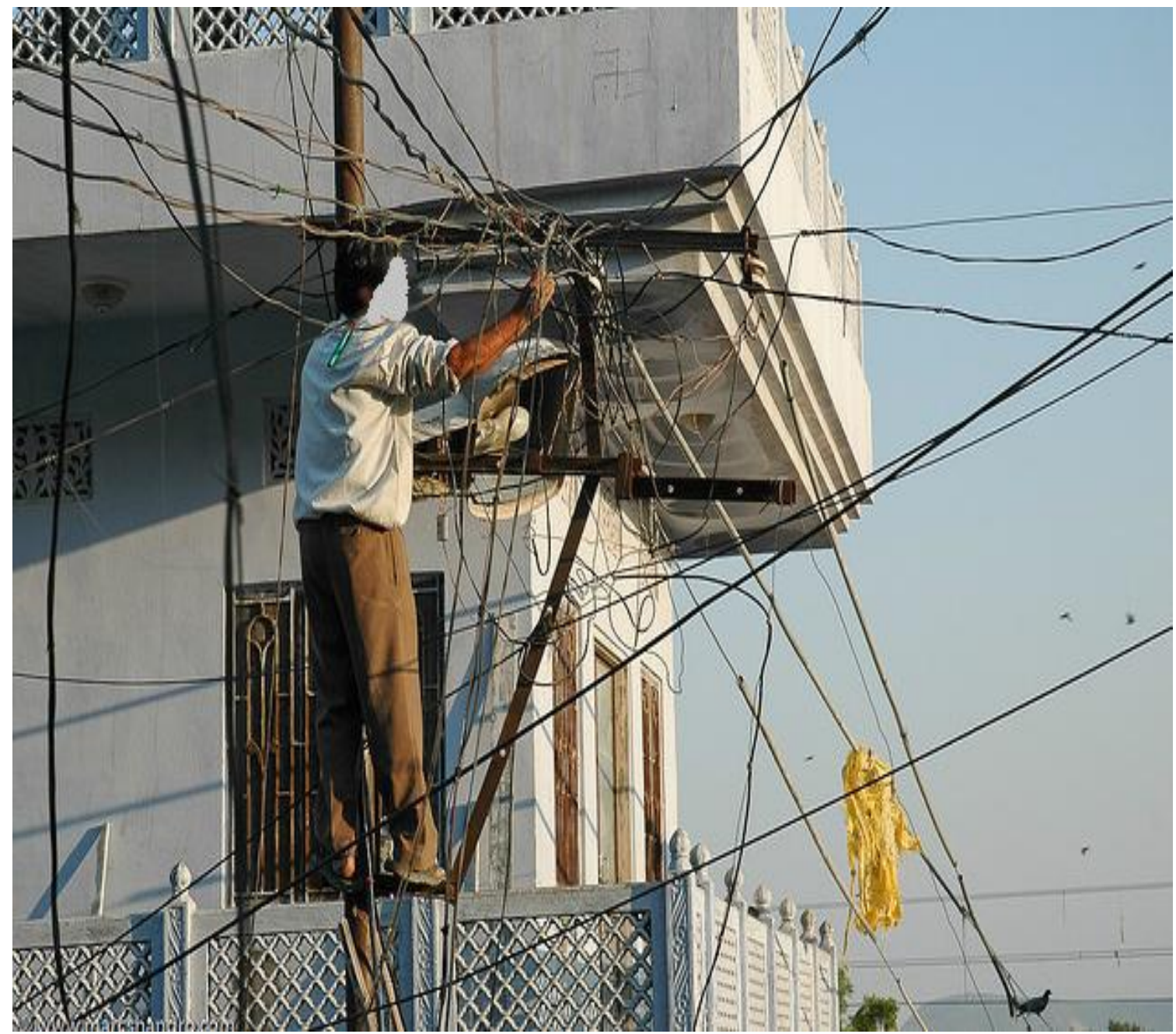

Figure5.Tapping on electrical line [8]

\subsection{Billing irregularities}

Jammu and Kashmir power department is very infamous for its billing irregularities. We have found many cases where unintentionally higher figures have been given but there are also cases where it is possible that employees have been bribed to record the meter at lower number than is shown. Consumer pays lower bill and meter-reader earns unofficial salary!

\subsection{Non realization of power bills}

Jammu and Kashmir power utilities have some chronic non payers of bills with government topping the list of defaulters. The gap between the amount billed and revenue collected in Jammu and Kashmir power development department (PDD) for 2012-13 was 80.08 crore. The billed amount according to official figures, was Rs1601.51 crore while revenue collection stood at Rs 1521.43 crore. The losses are expected to remain high in the coming financial years as well and the losses predicted for 2013 to 2016 are given below [11].

\begin{tabular}{|l|l|l|}
\hline $2013-2014$ & $2014-2015$ & $2015-2016$ \\
\hline 69.75 & 58.31 & 41.7 \\
\hline
\end{tabular}

Table1.predicted billed amount-revenue collection gap [9]

\section{DAMAGED DISTRIBUTION NETWORKS AND UNMETERED REGIONS}

Generally the grid is connected to the load centers through a sub -transmission network. These lines terminate in a substation where the voltage is stepped down to $11 \mathrm{kv}$ for power distribution networks to the last mile connections. The length of these lines up to the last mile connections is around $4 \mathrm{~km}$ in urban areas and $8 \mathrm{~km}$ in rural areas. These unduly long feeder lines lead to low voltage at end connections. In Kashmir where heavy snowfall occurs during winters, serious damage is caused to these lengthy distribution lines which mostly are laid in an unplanned manner. Rural areas are the worst sufferers. 


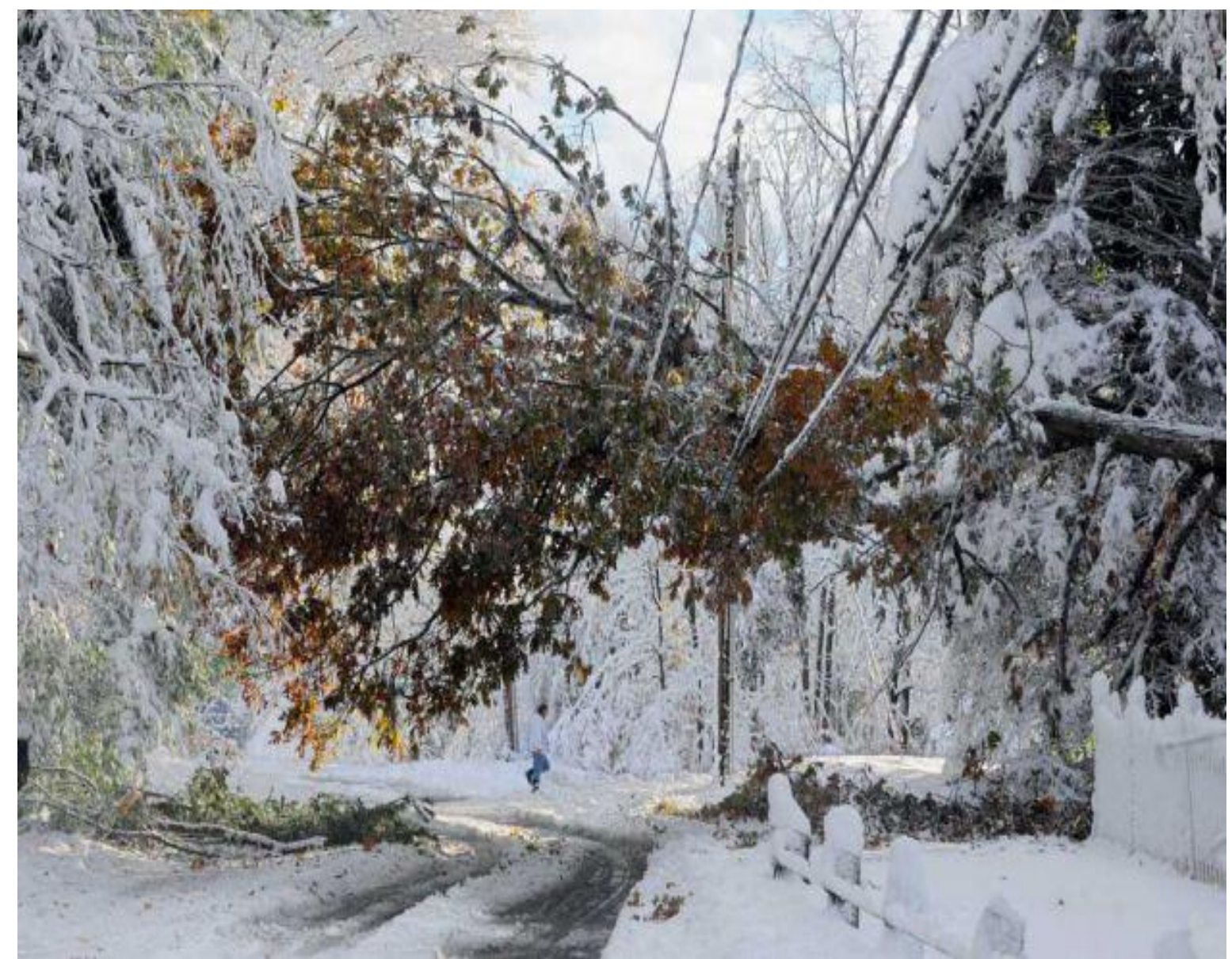

Figure 6 damaged distribution lines due to heavy snowfall [10]

Rural areas in Jammu and Kashmir are also unmetered thus huge amount of power is stolen particularly during winters which are lean season for power generation. There is no mechanism in place as we have found during our studies that power utilities are unable to install the meters because first, there distribution system is not in a position to guarantee a $24 \mathrm{hrs}$ supply. There are on average $10 \mathrm{hr}$ daily power cuts in some areas. It was also found that it will take a few more years for the department to overcome the backlogs for metering as shown below.

\begin{tabular}{|l|l|l|l|}
\hline & & Cumulative Number of Connections & Details of electronic meters installed \\
\hline S NO. & YEAR & & \\
\hline 1 & $2006-07$ & 1192698 & 149206 \\
\hline 2 & $2007-08$ & 1202649 & 370950 \\
\hline 3 & $2008-09$ & 1218036 & 411313 \\
\hline 4 & $2009-10$ & 1239180 & 454513 \\
\hline 5 & $2010-11$ & 1277369 & 509685 \\
\hline 6 & $2011-12$ & 1332036 & 588694 \\
\hline
\end{tabular}

Table2.Consumers registered and meters installed [11]

\section{CONCLUSION}

From the above discussion we conclude that Jammu and Kashmir power distribution system losses are untenably high specifically at the last mile low tension network, theft of electricity is widespread, outdated equipments are still in use, huge unaccounted consumption beyond agreement load and unregistered consumers are still big challenges for the utility. Concerned authorities need to take some strategic decisions so that losses are at least brought down up to the national average level. We also conclude that" financial viability of power sector is widely dependent on the reforms in distribution sector "[12]. The approaches taken, over the years, have created a worst distribution network that is highly inefficient. In order to reduce losses we have formulated certain suggestions that are given below 
- A high voltage distribution system (HVDS), currently functional at some places, should be expanded to thinly populated areas as losses for given power are inversely proportional to the square of its operating voltage. Higher the voltage, lesser are losses.

- Similarly aerial bunched cables (ABC) should be introduced in the congested areas. It will reduce the losses caused by illegal hooking in congested areas where HVDS is not feasible.

- Points of electrical installations should be carefully chosen close to the centre of gravity of consumers called as load centers as these could represent up to 5\% [12] of unaccounted electrical power consumption.

- Information technology should be used for better load management and efficient auditing.

- $\quad$ GIS mappings of electrical networks should be used for indexing of consumers.

- Government should generously fund the department in order to bring it out of financial insolvency.

\section{REFERENCES}

[1] Animesh pal, power sector in India, growth policies and challenges, international journal of emerging technology and advanced engineering. Volume 3, special issue 3, ICERTSD2013, Feb 2013, pages527536

[2] http//www.kashmirlife.com/mohra_hydroelectric_plant

[3] http//www.jkpdd.gov.in/about_us

[4] Report on "the performance of state power utilities", power finance corporation final report (annexure 1.1.0-1.5.3)

[5] Report on "the performance of state power utilities", power finance corporation final report, collection efficiency

[6] www.kashmirreader.com/kreadernew-'pdd-revenue-in-kashmir-up-by-28\%'

[7] Thomas B. smith electricity theft: a comparative analysis, Elsevier energy policy 32(2004) 2067-2076

[7] http ://www.operationkhanyisa.co.za/blog/entry/pay-it-forward-report-electricity-theft-a- photo-essay

[8] http://www.flickriver.com/photos/mshandro/35000426/

[9] www.kashmirreader.com/power woes: billed amount-revenue collection gap increasing

[10] www.gervilgroup.com/images

[11] Survey wing, power development department.

[12] greaterkashmir.com/news/2012/jan12/compensating-the-losses-7.asp 